\title{
PRODUCT CROSSING: DESIGNING CONNECTIONS USING A PRODUCT EXAMPLE.
}

\author{
T. Bleuzé ${ }^{1,2}$, J. Ceupens ${ }^{1}$, P. De Baets ${ }^{2}$ and J. Detand ${ }^{1}$ \\ ${ }^{1}$ Howest Industrial Design Center, University College of West-Flanders, Associated member of Ghent \\ University, Belgium \\ ${ }^{2}$ Ghent University, Laboratory Soete, Belgium
}

\begin{abstract}
Today, more and more products are made with multi materials, hybrid materials and composite materials to fulfil the more and more requiring product needs. Therefore connections and joints play a key role in (product) design. How to connect different parts remains one of the core questions in the design of products. In practice designers often fall back on a few known joining solutions. Tools like a joining selection software can be useful but can also limit the creativity of the designer. Certainly, in the beginning of the design process. Existing creativity techniques, which are suitable for all types of problems, can be used, but are mostly holistic and superficial. Therefore there is a need for divergent and inspirational techniques that focuses on the design of products and their connections. In this paper the authors discuss an experimental method called "product crossing", in which a real product is used as inspiration during the idea generation. The method was tested with several students with different backgrounds (industrial (product) design and mechanical design). They translated product properties and aspects of the example product in the specific context of their design which resulted in surprising product idea's. The different test cases are also discussed in this paper.
\end{abstract}

Keywords Product design, joining methods, creativity technique, product examples, product properties

\section{INTRODUCTION}

The world of today is a materialized world. People are surrounded with many different products. From a simple toothpick to an aerodynamic airplane, all these things, defined as products, are designed by humans. These products interact with humans, with other products and with the environment. A product can be a consumer good, an industrial machine, a piece of furniture, a vehicle, ... They are designed for some reason: they fulfil a need, they have a function. The ideal product or structure would be made out of one part, without the use of joints. Joints are mostly weak points in a product or structure. Actually the most products contains more than one part for several reasons [1]. E.g. to achieve functionality, to facilitate the manufacturability of a product, to minimize the cost or to provide aesthetics.

A connection can be defined as an interface between parts or functions. This interface can be virtual or physical, permanent or removable, flexible or fixed. The connection could be integrated into the parts or could be an external part or process. Hundreds different joining methods and connections are already developed in the past. These are mostly material dependent. Wood joinery, textiles, steel constructions, plastic parts, ... they all have their typical used joining methods. Today, an increasing number of products are made with different materials to fulfil the more and more requiring product needs. One of the core questions during the design of products remains how to join the different parts. In practice designers often fall back on a few known joining solutions.

\section{BENCHMARKS: EXISTING DESIGN TOOLS AND TECHNIQUES}

Several tools are already developed to help designers select joining methods. One of the most known tools is Granta Design [2] developed at Cambridge University. It is a software program and methodology that helps designers and engineers choose the best material for their application. A part of the software is dedicated to the selection of production and joining processes. Other tools are available on the internet. Archetype Joint [3] is a consulting firm specialised in joint design, tests and validation. Their website contains a free online tool for selecting fastening and joining methods that meet the joint requirements. Dunneplaat-online [4] is a result of a research in association with FME, TNO and TU Delft. This website gives information about the different ways to join sheet metal parts. A free online selection tool can be used to find the best joining method. Another example is the Adhesive toolkit [5], an online selection tool for 
adhesives. This was developed by the major research and technology organisations in the UK. Research at VUB/ULB [6] has the aim to develop a multi criteria decision-aid system for joining process selection at the early product design stage. A software application and decision-aid method called PROMETHEE supports the joining process selection. All these tools are very effective and can be helpful during the design process but still show some disadvantages. They have only a limited quantity of joining methods in their database and the tools don't stimulate the creativity of the designer. They can even limit the designers creative freedom. Certainly during the concept generation of products.

Actually, industrial designers don't select joining methods, they should design connections as an integral part of the product. Existing creativity techniques can be used to generate ideas. The existing creativity techniques [7], which are mostly suitable for all types of problems, can be used but are holistic and superficial. Using these techniques for finding new or other joining solutions takes also a lot of time. Therefore there is a need for divergent and inspirational techniques that focuses on the design of products and their connections that can also be used in the early stage of the design process. The Design to Connect (D2C) research project has the aim to develop several of these tools and techniques to support designers without losing their creative freedom. This paper discusses a first experimental technique to inspire designers during the first phases of the design process.

\section{PRODUCT CROSSING}

\subsection{Elementary design properties}

As mentioned before, designers don't select connections, they design connections as an integral part of the design process. The product is designed to fulfil some requirements. In the theory of product properties [8] [9] a product has internal and external properties. The relations of a product with its surroundings (user, other product, systems, ...) are defined as external properties. The relations between different parts in the product are defined as the internal properties. With these properties the product must fulfill the predefined requirements. When a designer designs a physical product he/she considers the different parts of the product. In material selection, a part is defined by four considerations according to Ashby [10]: Function, material, geometry and manufacturing process. The designer also considers the relation and structure between the parts, defined as the product architecture or product structure and the connections between the parts. This results in six considerations:

- $\quad$ The material of a part: the designer must select the material (metal, wood, plastic, ...) and material form (textile, sheet, foam, ...) of the different parts in the product considering the product requirements: strength, ergonomics, ...;

- $\quad$ The production process of the product and its parts: the designer must also select how the product and its parts are manufactured. (extrusion, moulding, ...);

- The geometry of the product and its parts: the designer must define the shape of the product considering the product requirements: usability, manufacturing, aesthetics, personality of the product ...;

- $\quad$ The function of the product and its parts: there are different ways to fulfill a function. The designer must explore different solutions and select the best for the specific context;

The product structure: when the global shape of a product is defined, there are still different ways to build up the product. The designer must design the product structure as it influences the assembly process of the product;

The connections: the connections are centred in the framework because this is the starting point of this research. The designer must design the different connections in the product (processes, parts and integral attachments).

These considerations are defined in literature as 'the elementary design properties': "With the elementary design properties as the only means, the designers should fulfil all the requirements set on a product by giving it the necessary internal and external properties" [9]. The elementary design properties and the relations between them are shown in the framework [Figure 1.]. During the design process the designer manipulates these 'elementary design properties' simultaneously and in no specific order. They are all in relation with each other; when one property changes, it could also influence the others. It is possible to reduce connections in a product or to create other possibilities to change one of the five considerations around the 'connections' in the framework. This could be illustrated with an example. When a designer decides to create a product using injection moulding instead of a sheet metal product, he/she creates new possibilities for joining parts. Some parts could also be merged and other shapes (geometry) are possible. In that way the product structure could also change. 


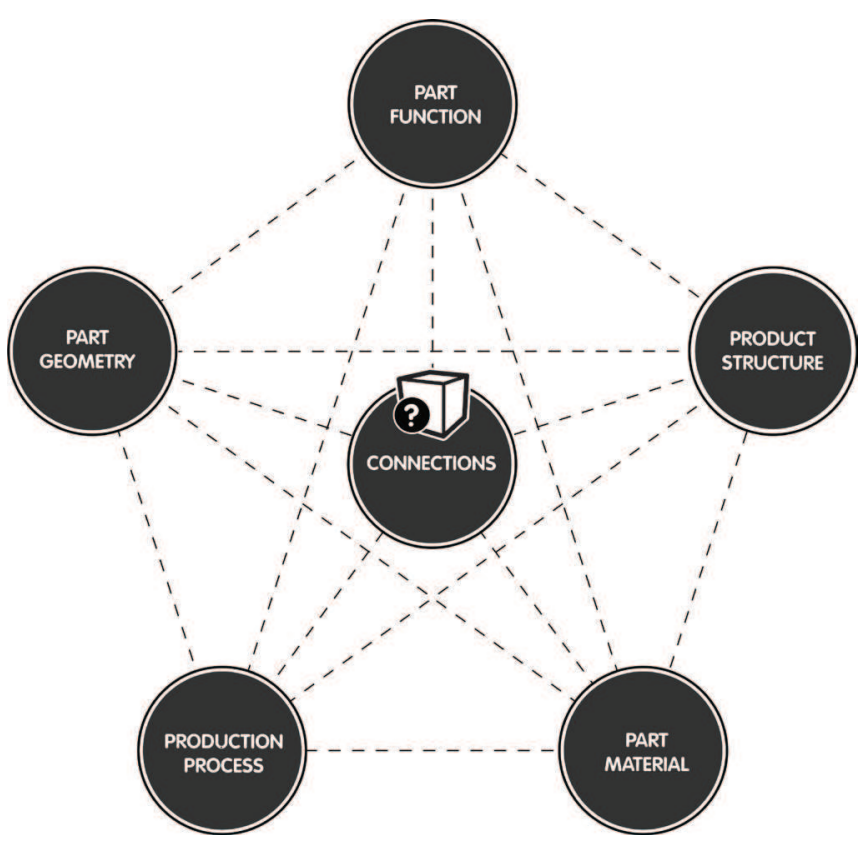

Figure 1. The elementary design properties framework

\subsection{Forced analogy}

The technique discussed in this paper is called 'product crossing'. It will proceed as follows. During the idea generation phase the designer or design team gets an inspirational product to focus on. They analyze the product and translate aspects of the product in their own context. The name 'product crossing' is inspired on the term 'plant crossing'. Plant crossing is the art and science of combining properties of two plant species to create a new variety. In 'product crossing' designers combine aspects from the inspirational product to their own design and create a 'new' product. This technique is based on forced analogy [11], a creativity technique. Forced analogy is a problem solving technique based on non-typical associations. The idea behind this technique is to compare the problem with something else that has little or nothing in common with the problem. Using forced analogy results in new and surprising insights.

\subsection{Product examples}

Designers are visually oriented. Good designers have the attitude to look to their surrounding and to other products for inspiration. They don't copy other products but learn from them and use some aspects in a different context and add some new elements to create a new product. A real product communicates much information in a very concentrated way. A product illustrates material and manufacturing properties, it gives a certain feeling or meaning, some parts solve a technical problem, ... Therefore it is very interesting to use a real product as inspiration to focus on. The technique, using inspirational products, was tested with a representative sample of design and engineering students. Some of the products used in the test are shown in Figure 2.
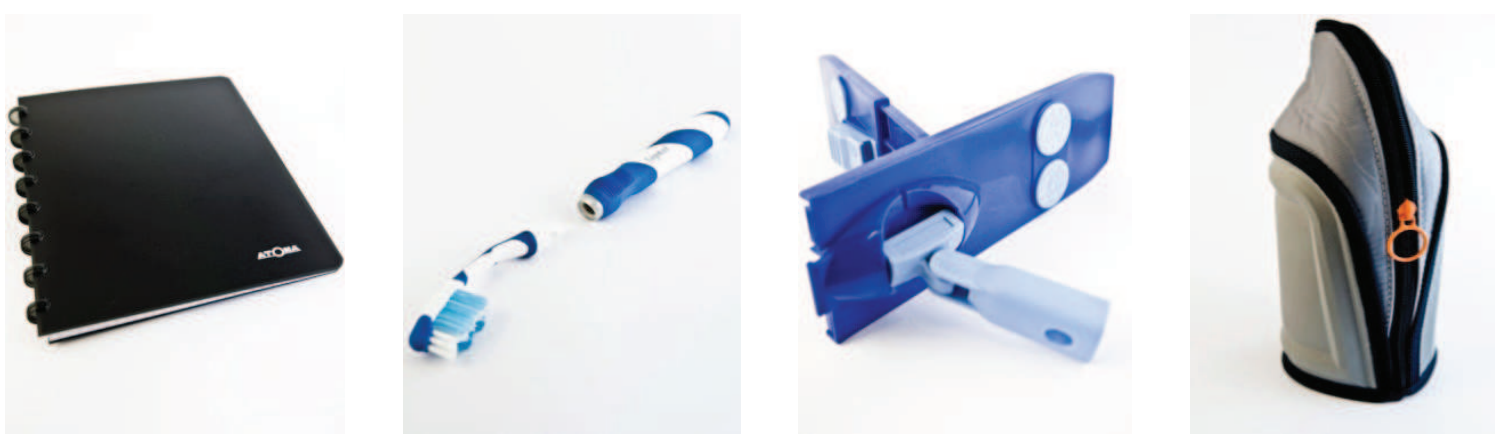

Figure 2. Some inspirational products used in the test:

$\begin{array}{llll}\text { 1. Atoma notebook } & \text { 2. modular toothbrush } & 3 \text {. sweeper system } & 4 \text {. bottle bag }\end{array}$ 
In essence it makes no difference which products are used as inspiration, but the best results were obtain with products that meet these conditions:

- None of the products deal with the context of the case (cfr. 3.2 Forced analogy). If a table is to be designed no other table or chair should be used as inspiration. A product from a total different context must be used: e.g. a toothbrush, a measuring tape, ...

- The products are composed of different parts but are not too complex. (max. 20 parts) The functionality of the products could be easily distracted.

- The products could easily be (partially) assembled and contained different connection methods.

\section{TEST CASES}

\subsection{Approach}

The 'product crossing' technique was tested with a relevant sample of design and engineering students. The test had two aims. Firstly to verify if the students recognised the elementary design properties in the example products and used them in their own design. Secondly to check if the 'product crossing' technique generated different and surprising ideas. This resulted in two questions to answer:

- Did students use (unconscious) the 'elementary design properties' in their own design?

- Can new and creative ideas been created, using a product from a total different context?

Obviously the framework was not shown to the students. The students worked together in teams of three. Three different cases were defined as starting point:

- a mailbox that could be attached to different pole diameters;

- a coat rack that could be connected to an existing door;

- a planter that could be attached to an existing balustrade.

The selected cases where not to complex, because the students had to realise their ideas in one block of three hours. All the cases contained also a specific joining problem because this is the focus of the research. The test was focussed on the idea generation phase in the design process. Every team had to design different concepts for one of the three cases. Each group also received a different inspirational product. During the design of the concepts they had to focus on this inspirational product and its aspects. This exercise was done three times, each time with other students with a different educational background:

- Master students Civil Engineering (Ghent University, 11 groups)

- Master students Industrial Design (Howest, 8 groups)

- Bachelor students Industrial Product Design (Howest, 19 groups)

In that way it was also possible to evaluate if there's a difference between the 'traditionally educated' civil engineer students and the more 'creatively educated' industrial (product) design students. The students sketched their ideas on paper during the exploration phase. These so called 'design drawings' [12] do not have the aim to communicate with others but are a part of the thinking process of the designer or design team. An example of design drawings made during the exercise is shown in Figure 3. The students were also asked to indicate on their drawings which aspects of the inspirational product they used in their ideas. Finally the students had to draw an exploded view or a presentation drawing of their total concept.

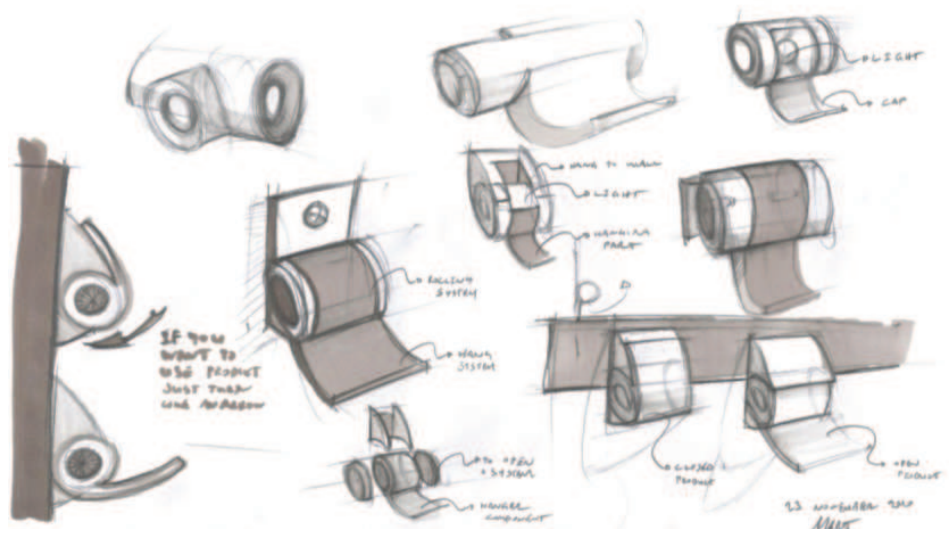

Figure 3. Design drawings made by students. 


\subsection{Results}

The exercise provided surprising ideas. Six ideas are explained in this paper. It is important to notice that the idea's are developed in a three hours exercise and are still on a conceptual level. They are not fully technical developed.

\subsubsection{The 'toothbrush' - mailbox}

In this case the students had to design a mailbox with a toothbrush as inspirational product. The students were inspired by a material (material form) of the toothbrush: the brush hairs. The result is a mailbox that is build with brush hairs. The user can 'post' the letters between the brushes. They created a mailbox with a total different product architecture, without the use of hinges. By its construction the mailbox can be water proof. This idea was found by students Master Civil Engineering. Students Master Industrial Design had a similar concept. (Figure 4.)
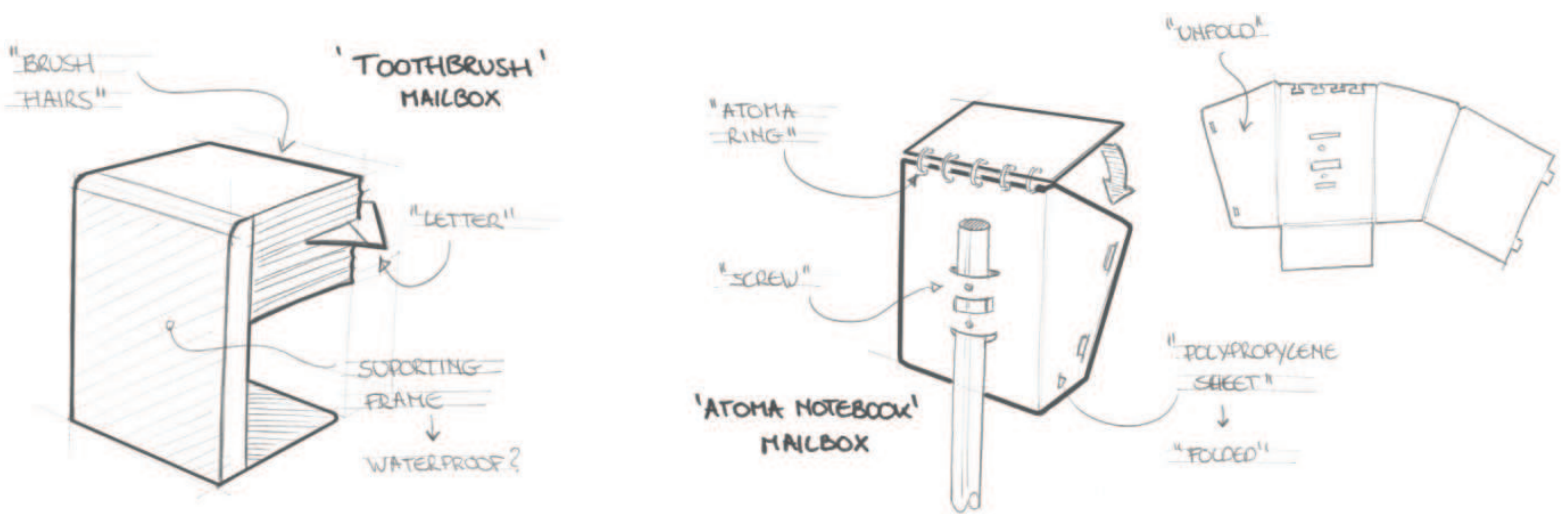

Figure 4. Concept sketches:

1. 'toothbrush' - mailbox, 2. 'Atoma notebook' - mailbox

\subsubsection{The 'Atoma notebook' - mailbox}

The second case is another idea for a mailbox. Here the students received an Atoma notebook as inspirational product. The result is a mailbox made with polypropylene sheet material. This was the material where the cover of the notebook was made of. They used also the typical connections of the notebook as hinge for the mailbox. The mailbox is aligned to the pole by its shape and attached with two screws, as shown in figure 4. This idea was generated by students Master Industrial Design.

\subsubsection{The 'tape rule' - coat hanger}

The third idea is a concept for a coat hanger (Figure 5.). The students must designed a coat hanger with a tape rule as inspirational product. They used the functionality of a tape rule as inspiration: the retracting mechanism. The idea is a coat hanger with adjustable height. Therefore the hanger can be used by adults and children. The students also used the geometry of the tape rule, because it is typical for the mechanism. The coat hanger is attached to the door using a simple screw. This connection is not visible because the screw is located on the top of the door. This idea was generated by students Master Civil Engineering.
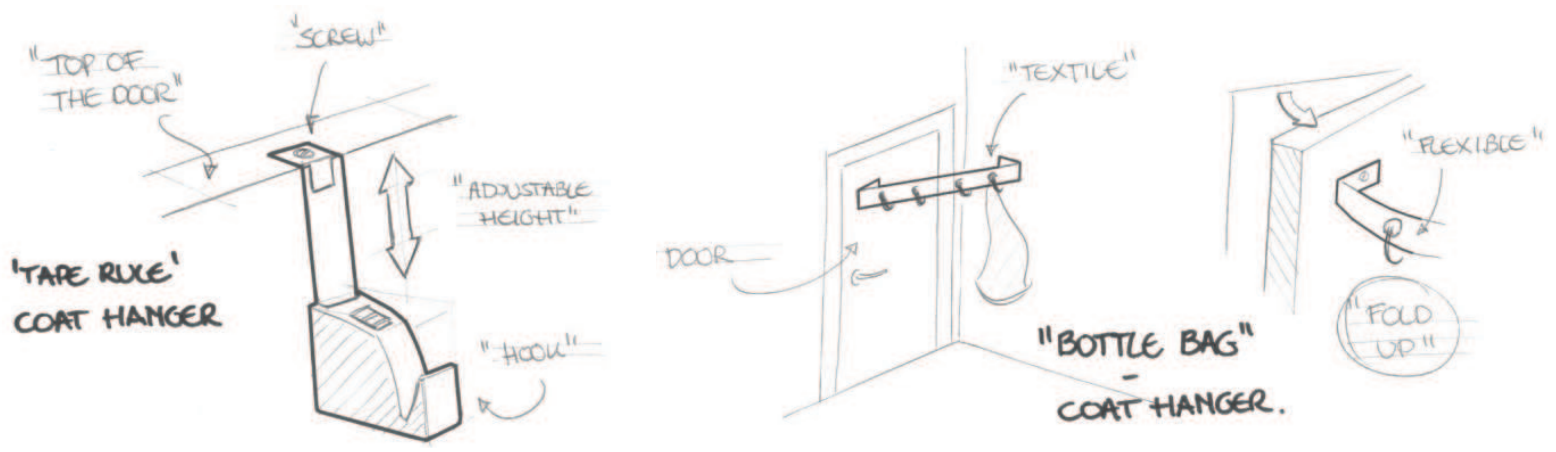

Figure 5. Concept sketches:

1. 'tape rule' - coat hanger, 2. 'bottle bag' - coat hanger 


\subsubsection{The 'bottle bag' - coat hanger}

This is another idea for a coat hanger. In this case the inspirational product was a bag for holding a drink bottle. The flexible fabric (material) which was used in the bag was the inspiration for the students. They created a coat hanger made with fabric that can be attached between a door and the wall (Figure 5.). There must be one requirement. The door must be located in a corner of the room. When a person opens the door, the coat hanger will fold. The hooks are stitched to the fabric and the fabric is attached to the wall and the door using screws. This idea was found by students Master Civil Engineering.

\subsubsection{The 'flashlight' - planter}

This is a concept of a planter that could be attached to an balustrade, designed by students Bachelor Industrial Product Design (Figure 6.). It was found using a flashlight as inspirational product. The flashlight could be attached on the head of the user using straps. The students used this material, the straps, as inspiration. They created loops with a hook and loop fastener (velcro) to attach the planter to the balustrade. Because its flexible interface it is possible to attach the planter to different existing balustrades.
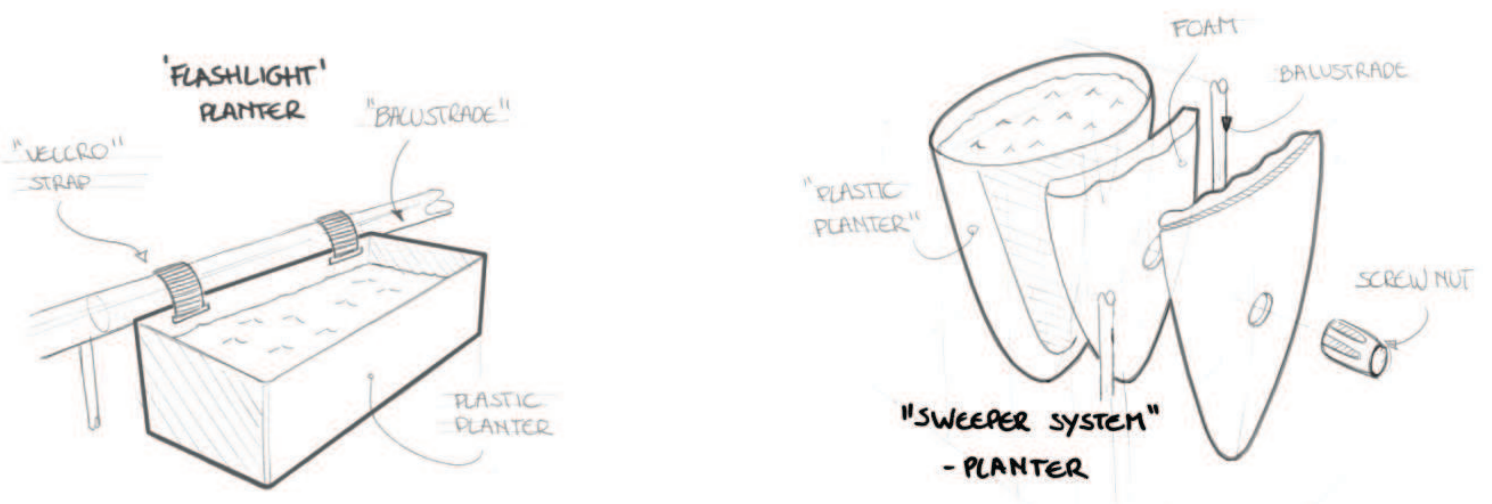

Figure 6. Concept sketches:

1. 'flashlight' - planter, 2. 'sweeper system' - planter

\subsubsection{The 'sweeper system' - planter}

The second concept of the planter could be attached between the balustrade. (Figure 6.) In this case the inspirational product was a sweeper system. The students used the material of the sweeper system as inspiration: the plastic and the foam material. They used also the connection between the sweeper system and the shaft: a screw nut. The balustrade is clamped between the two parts. The foam material prevents damaging the balustrade. This concept was found by students Bachelor Industrial Product Design.

\section{DISCUSSION}

The test had two aims: Firstly to verify if the students recognised the elementary design properties in the example products and used them in their own design. Secondly to check if the 'product crossing' technique generated different and surprising ideas. Beside this it was also possible to verify if there was a difference between the test groups.

\subsection{Did students use (unconscious) the 'elementary design properties' in their own design?}

One aim of the test was to check if designers (in this case design and engineering students) recognised unconscious the elementary designs properties in the example products. The students were asked to indicate on their drawings the aspects of the inspirational products they used in their new design. They used different aspects of the inspirational products. In general the used aspects can classified in these groups:

- Material aspects: a specific material (ex. polypropylene, aluminum, ...) properties of a material (ex. flexibility, color, ....) or a material form (ex. fabric, sheet, ...);

- Geometrical aspects: details and forms used in the inspirational product;

- Functional aspects: the functionality of a product or part (ex. flashlight: give light);

- Connections: specific connection methods from the product are translated in the new context;

- Production process: students designed with a specific production process in their mind used in the example product (ex. injection molding, extrusion, ...); 
Material, geometry, connections, production process and functions are five of the six elementary design properties shown in the framework. (Figure 1.) The elementary design property 'structure' defined in the framework was not mentioned by the students during the test. Probably because this is an abstract understanding. It could be derived from the sketches of the students that in some cases the students unconscious translated the structure of the example product to their own context. This could be explained because the structure of a product is related to the other design properties.

The production process was only mentioned by a few students Industrial (Product) Design. The production process of a product is difficult to distract without specific knowledge of the production process. Other aspects like geometry, material properties of functions are easier to see without specific background knowledge. The students did use (unconscious) the 'elementary design properties'.

The framework (Figure 1.) could also be used to map a design problem definition. It is possible to see which design properties are already defined and which can still vary. E.g. a table that must be designed in steel. In this case the material (steel) and the main function of the product is already defined. The designer can still explore different geometries, structures, production processes and joining methods to create a table. By seeing the framework the designer can think conscious about the different design properties and possible solutions. This framework can be further developed in future research.

\subsection{Can new and creative ideas been created, using a product from a total different context?}

In general the results of the product crossing technique generated surprising ideas that could not be created without seeing that specific example product. During the test with students it was noted that the teams found several creative ideas using the technique. This was a first iteration in the design process. The students were also ask to combine several ideas and create one total concept. In this second iteration they worked out their creative idea. Then almost all the teams fall back on known and frequently used joining solutions. They used bolts and screws as a connection method and didn't questioning this solution.

This can be explained with a psychological phenomena. In the book 'How designers think' [12] Bryan Lawson wrote that many studies have demonstrated the mechanising effect of experience. Abraham Luchins was the first to describe this effect experimentally with the water jar test in 1942. The experiment's participants had to figure out how to measure a certain amount of water using three water jars. Each jar had a different capacity. The test persons used the same method they had used in a previously test to solve a new but similar problem. Even there were better and more efficient solutions for that specific problem. In psychology this effect called the 'einstellung (set) effect': "This effect occurs when the first idea that comes to mind, triggered by previous experience with similar situations, prevents alternatives being considered." [13]

In design contexts this effect is defined as 'design fixation': "Fixation occurs when a designers experiences an example of an existing design, and then he/she creates a new product with features similar to the prior example" [14]. When a designer uses a product as inspiration from a total different context, as applied in the 'product crossing' technique, he/she is forced to create new insights and analogies. The German word 'einstellung' means 'attitude'. Actually a good designer has the attitude to questioning every solution or step in the design process and considering alternative solutions. In practice designers which have much experience in one company or sector didn't consider alternative solutions or they have difficulties to find new and 'out of the box' solutions. Especially for practical aspects like joining parts in a product or structure.

\subsection{Was there a difference between the three test groups?}

The test was done three times, each time with a different group of students. Expected was that students Industrial (Product) Design created more creative and "out of the box" ideas, because this is a part of their education. By analysing the results of the test there was no obvious difference between the students Civil Engineering and the students Industrial (Product) Design. When people are triggered or forced to think in alternative ways (in this case by receiving a product from a total different context), surprising and new ideas are created. The only restriction is their own imagination. The quality of the results was mostly depended from the motivation an cooperation from the team of students.

\section{CONCLUSIONS}

People often fall back on known solutions and don't consider other and even better solutions. In the first iteration the students created new and creative ideas. In the second iteration they mostly used the known solutions and did not consider others. Therefore it is interesting to do future research how designers could be stimulated to consider many solutions for a specific joining problem. Knowledge and experience can have a mechanising effect and prevent finding new and better solutions. This is one of the reasons why there is a need for divergent and creative tools that could help designers. Good designers have already the 'attitude' to consider (unconscious) many solutions for a (connection) problem. 'Product crossing', the 
technique discussed in this paper, is a useful and inspirational technique for designers who are designing a physic product and its connections. The technique is best used in the early stage of the design process (concept generation) because using this the students generate different and divergent solutions. The tool is not a 'magic hat' that generate creative solutions. The success of using this tool is still mainly dependent from the creativity of the designer or the design team. The tool can be further developed to a complete creativity technique. It could be a box that contains different types of inspirational products. Designers or design teams could used them to focus on during a brainstorm. Further research within this project will focus on how designers could be stimulated to generate different solutions for connections during the different iterations of the design process. This with using different tools and physical prototyping techniques. Recent research showed that physical prototyping could help designers to decrease the effect of design fixation. [14] This 'hands on' approach is also the basis of the design education in Howest University. [15]

\section{REFERENCES}

[1] J. R. W. Messler, "Joining of materials and structures", Elsevier, 2004.

[2] Granta Design CES selector. Available: www.grantadesign.com

[3] Archetype joint. Available: www.archetypejoint.com

[4] Dunne plaat online. Available: www.dunneplaat-online.nl

[5] Adhesive toolkit. Available: www.adhesivestoolkit.com

[6] T. L'Eglise, et al., "A Multicriteria Decision-Aid System for Joining Process Selection," in IEEE International Symposium on Assembly and Task Planning (ISATP 2001), Fukuoka, Japan, 2001.

[7] Innowiz, Industrial Design Center, Howest University. Available: www.innowiz.be

[8] N. Roozenburg and J. Eekels, "Productontwerpen, structuur en methoden", Lemma, 1998.

[9] G. Johansson, "Product innovation for sustainability: on product properties for efficientdisassembly," International Journal of Sustainable Engineering, 2008.

[10] M. F. Ashby, "Materials selection in mechanical design", Third edition, Elsevier, 2005

[11] M. S. Slocum, "Developing forced analogies creates new solutions", Real innovation Available: www.realinnovation.com/content/c080317a.asp

[12] B. Lawson, "How designers think: the design process demystified", Fourth edition, Elsevier, 2005.

[13] M. Bilalic, et al., "Why good thoughts block better ones: The mechanism of the pernicious Einstellung (set) effect," Cognition, 2008.

[14] R. J. Youmans, "The effects of physical prototyping and group work on the reduction of design fixation," Design Studies, 2010

[15] J. Detand, et al., "The role of prototyping in product development.", 2010 